\title{
A NEWLY-DEVELOPED MODEL FOR PREDICTING CUTTING POWER DURING WOOD SAWING WITH CIRCULAR SAW BLADES
}

\author{
Kazimierz, Orlowski ${ }^{1, \AA}$, Tomasz, Ochrymiuk ${ }^{2}$
}

\begin{abstract}
In the classical approach, cutting forces and cutting power in sawing processes of orthotropic materials such as wood are generally calculated on the basis of the specific cutting resistance $k$ (cutting force per unit area of cut). For every type of sawing kinematics (frame saws, band saws and circular sawing machines) different empirical values of specific cutting resistance $k_{c}$ have to be applied. It should be emphasised that sources in the scientific literature and handbooks do not provide any information about wood provenance, nor about cutting conditions in which cutting resistance had been determined. In analyses of sawing processes in which the offcut is formed by shear, Atkins's ideas that all cutting forms a branch of elastoplastic fracture mechanics can be applied. Thanks to this modern approach it was possible to reveal, using experimental results data of fracture toughness and shear yield stresses of Polish pine (Pinus sylvestris), the significant effect of the raw material provenance (source of wood) on cutting power. In the common model for circular sawing machine kinematics, which is similar to metal milling, the sum of all uncut chip thicknesses of the all the teeth simultaneously engaged represented the mean uncut chip thickness. In this work predictions of the newly-developed model for the circular sawing machine are presented. In the model, beside uncut chip thicknesses changes, appropriate changes in shear yield stress and toughness with tooth/grain orientation have been taken into account. The conducted analyses have demonstrated that values of RMS of cutting power obtained with the new developed model are slightly larger than experimental values. On the other hand computed values of cutting power with the use of the mean uncut chip thicknesses in the model are a bit lower from the empirical one.
\end{abstract}

Keywords: Circular sawing machine, cutting, fracture mechanics, fracture toughness, modelling, orthotropic material, sawing process, wood.

\section{INTRODUCTION}

Theoretical and experimental determination of values of forces acting in the cutting process belongs to the fundamental and simultaneously the most explored field of mechanics of the machining process. The process of cutting is analyzed in fracture mechanics terms with a view to quantifying the various parameters involved. The governing parameters in the models (predominantly of orthogonal cutting) are tool geometry, which are principally the rake and wedge angles, geometry of the uncut chip (mainly its thickness), the machined material properties yield stress and fracture toughness, and

${ }^{1}$ Professor, Gdansk University of Technology, Faculty of Mechanical Engineering, Department of Manufacturing Engineering and Automation, Narutowicza, Gdansk, Poland.

${ }^{2}$ Science researcher, the Szewalski Institute of Fluid-Flow Machinery, Polish Academy of Sciences, Centre of Flow and

Combustion, Gdansk, Poland. tomasz.ochrymiuk@imp.gda.pl

•Corresponding author: korlowsk@pg.gda.pl

Received: 09.05.2016 Accepted: 09.01.2017 
friction conditions between chip and rake surface (Atkins 2003, 2005, 2009, 2016, Williams et al. 2010, Williams and Patel 2016, Wyeth and Atkins 2009, Wyeth et al. 2009).

Wood may be described as an orthotropic material; having unique and independent mechanical properties in the directions of three perpendicular axes: longitudinal, radial, and tangential. The longitudinal axis direction is parallel to the fibers course. The radial axis is normal to the growth rings, while the tangential axis is perpendicular to the grain but tangent to the growth rings (Kretschmann et al. 2010, Laternser et al. 2003, Porankiewicz and Goli 2014). These specific features might be taken into account in analyses of energetic effects thanks to building surface energy for separation (i.e. material's fracture toughness) into the models for forecasting of energetic effects (cutting force or cutting power). In wood cutting processes it could be emphasised the use of some elements of fracture mechanics: in the calculation models of cutting forces developed by Laternser et al. (2003), analyses made by Merhar and Bučar (2012), theoretical and experimental studies of sawing of pine wood on sash gang saws by Orlowski and Palubicki (2009), in theoretical and empirical studies of circular sawing by Hellström et al. (2013) and Kopecký et al. (2014), in experimental studies on formation of wood surfaces and chips by Marchal et al. (2009).

Otto and Parmigiani (2015) in discussion of their empirical results of the sawing process noticed that shear yield stresses and fracture toughness of the cut raw material could be useful for better explanation of some saw-chain cutting mechanics phenomena, in numerical simulation of orthogonal cutting problems Nairn (2015) described a method called the material point method. The latter has been applied for numerical modelling of orthogonal cutting of wood with a bench plane, in which both full chip formation and the crack growth were able to be simulated (Nairn 2016). Such simulations can be used to optimise woodworking with a bench plane.

The sawing process with circular saw blades experimentally has been investigated in the laboratory conditions Beljo-Lučić et al. (2004), in case of industrial conditions by Cristóvão et al. (2013), and for wood crosscutting process (Krilek et al. 2014).

The presented by Orlowski et al. (2013) analytical analyses of energetic effects with the use of cutting models that include work of separation in addition to plasticity and friction corroborated their versatility and revealed the usefulness for every known type of sawing kinematics. The same methodology was applied for forecasting of the capacity of every type of sawing machines (frame sawing machine, circular sawing machine and bandsawing machine), for the real sawing patterns used in the sawmill, in terms of available power, feed rates and so on, leading to comments on the design of machines with different kinematic features (Orlowski et al. 2014). In the common model for circular sawing machine kinematics, which is similar to metal milling, the sum of all uncut chip thicknesses of the all the teeth simultaneously engaged represented the mean uncut chip thickness (Orlowski et al. 2013, 2014). This work's goal was to demonstrate predictions of the newly-developed model for the circular sawing machine tool. In the proposed model, beside uncut chip thicknesses changes, appropriate changes in shear yield stress and toughness with tooth/grain orientation have been taken into account.

\section{THEORETICAL BACKGROUND}

Making an assumption that cutting force $F_{c}$ acting in the middle of the cutting edge is an equilibrium of forces related to the direction of primary motion for a single saw tooth the mechanical process of material separation from the sawn workpiece, i.e. chip formation, can be approximately described by the example of an orthogonal process (two dimensional deformation) (Orlowski et al. 2013).

In the case of circular sawing, identically as in analytical models for milling (Altintas 2000, Ammar et al. 2009, Budak 2006), the instantaneous uncut chip thickness $h_{j}(\varphi)$ at a certain location of the cutting edge (Figure 1) can be approximated as follows:

$$
h_{j}(\varphi)=f_{z} \sin \varphi_{j}
$$


where: $f_{z}$ is feed per tooth, $\varphi_{j}$ is the angular position of the $j$-th tooth (immersion angle), and its value changes as follows:

$$
\varphi_{j}=\varphi+(j-1) \varphi_{P} \quad j=1, \ldots, z
$$

$\varphi_{P}$ is the pitch angle defined as $\varphi_{P}=\frac{2 \pi}{z}$, and $z$ is number of teeth.

If $\phi_{e n} \leq \phi_{j} \leq \phi_{e x}$, then it has a value, otherwise it is null. $\phi_{e n}$ is an angle of teeth entrance which is given by $\phi_{e n}=\arccos \frac{2\left(H_{p}+a\right)}{D}$ (when the tool tooth gets into the workpiece for machining), and $\phi_{e x}$ is an exit angle (the tooth of the saw blade gets out of the workpiece) which can be determined as $\phi_{e x}=\arccos \frac{2 a}{D}, D$ is a diameter of the circular saw blade. In the case of cutting with circular saw blades the cutting power a new developed macro-mechanic model (Orlowski and Ochrymiuk 2013), which is based on the model proposed initially in work by Orlowski et al. (2013), can be expressed as:

$$
P_{c j}(\phi)=v_{c} S_{t}\left[\frac{\tau_{\gamma \| \perp_{-} j}(\phi) \cdot \gamma_{j}(\phi)}{Q_{\text {shear }_{-} j}(\phi)} h_{j}(\phi)+\frac{R_{\| \perp_{-} j}(\phi)}{Q_{\text {shear }_{-} j}(\phi)}\right]
$$

In the above model (Eq. 3) it was assumed that the cutting edges of teeth are sharp. Moreover, if we assume the cut is straight, and the cut deviation is low; then we can ignore the effect of lateral forces on the power consumption (Mohammadpanah and Hutton 2016a).

In Eq. (3) $\tau_{\gamma \| \perp_{-} j}(\varphi)$ is the shear yield stress, $\gamma_{j}(\varphi)$ is the shear strain along the shear plane, which is given by:

$$
\gamma_{j}(\varphi)=\frac{\cos \gamma_{f}}{\cos \left(\Phi_{c}\left(\varphi_{j}\right)-\gamma_{f}\right) \sin \Phi_{c}\left(\varphi_{j}\right)}
$$

$\beta_{\mu}$ is friction angle which is given by $\tan ^{-1} \mu=\beta_{\mu}$, with $\mu$ the coefficient of friction, $\gamma_{f}$ is the rake angle, $\Phi_{c}\left(\varphi_{j}\right)$ is the shear angle which defines the orientation of the shear plane with respect to cut surface, $R_{\| \perp_{-} j}^{j}(\varphi)$ is specific work of surface separation/formation (fracture toughness), and $Q_{\text {shear } j}(\varphi)$ is the friction correction:

$$
Q_{\text {shear } r_{-}}(\varphi)=\left[1-\left(\sin \beta_{\mu} \sin \Phi_{c}\left(\varphi_{j}\right) / \cos \left(\beta_{\mu}-\gamma_{f}\right) \cos \left(\Phi_{c}\left(\varphi_{j}\right)-\gamma_{f}\right)\right)\right]
$$

For least cutting force $F_{c}$, the shear angle $\Phi_{c}\left(\varphi_{j}\right)$ (for indirect tooth position) satisfies (Atkins 2003): 


$$
\begin{aligned}
& {\left[1-\frac{\sin \beta_{\mu} \sin \Phi_{c}\left(\varphi_{j}\right)}{\cos \left(\beta_{\mu}-\gamma_{f}\right) \cdot \cos \left[\Phi_{c}\left(\varphi_{j}\right)-\gamma_{f}\right]}\right] \cdot\left[\frac{1}{\cos ^{2}\left[\Phi_{c}\left(\varphi_{j}\right)-\gamma_{f}\right]}-\frac{1}{\sin ^{2} \Phi_{c}\left(\varphi_{j}\right)}\right]=} \\
& =-\left\{\cot \Phi_{c}\left(\varphi_{j}\right)+\tan \left[\Phi_{c}\left(\varphi_{j}\right)-\gamma_{f}\right]+Z\right\} \cdot\left[\frac{\sin \beta_{\mu}}{\cos \left(\beta_{\mu}-\gamma_{f}\right)}\left\{\frac{\cos \Phi_{c}\left(\varphi_{j}\right)}{\cos \left[\Phi_{c}\left(\varphi_{j}\right)-\gamma_{f}\right]}+\frac{\sin \Phi_{c}\left(\varphi_{j}\right) \sin \left[\Phi_{c}\left(\varphi_{j}\right)-\gamma_{f}\right]}{\cos ^{2}\left[\Phi_{c}\left(\varphi_{j}\right)-\gamma_{f}\right]}\right\}\right] \\
& \text { in which } Z=\frac{R_{\| \perp_{-} j}(\varphi)}{\tau_{\gamma \mid \perp_{-} j}(\varphi) \cdot h_{j}} \text { is the parameter which makes } \Phi_{c}\left(\varphi_{j}\right) \text { material dependent, on the }
\end{aligned}
$$

contrary to the classical approach by Merchant (Böllinghaus et al. 2009, Markopoulos 2013). Derivation of the formula (6) can be found in Appendix A.

Taking into account the position of the cutting edge in relation to the grains, for indirect positions of the cutting edge fracture toughness $R_{\| \perp_{-} j}(\varphi)$ and the shear yield stress $\tau_{\gamma \| \perp_{-} j}(\varphi)$ may be calculated from formulae:

$$
R_{\| \perp_{-} j}(\varphi)=R_{\mid} \cos ^{2} \varphi_{j}+R_{\perp} \sin ^{2} \varphi_{j} \tau_{\gamma \| \perp_{-} j}(\varphi)=\tau_{\gamma \mid} \cos ^{2} \varphi_{j}+\tau_{\gamma \perp} \sin ^{2} \varphi_{j}
$$

Accordingly to Orlicz (1988), who applied the plane stress transformation equation for determination of specific cutting resistance in indirect positions of the cutting speed direction, the same approach has been implemented for computation of the shear yield stress and fracture toughness as tensor values (Orlowski et al. 2013, Hlaskova et al. 2015). It ought to be emphasized that the same method is commonly used in general mechanics of materials to transform the stress components from one set of axes to another (Gere 2004).

Maximum, average or RMS (root-mean square) values of power can be determined after one full revolution of the tool, i.e. $\varphi$ : $0-360^{\circ}$ is simulated (Budak 2006). Thus, the total cutting power can then be computed as:

$$
P_{c}(\phi)=\sum_{j=1}^{j=z} P_{c j}(\phi)
$$

The obtained values from the Eq. 8 could be augmented by the chip acceleration power $P_{a c}$ variation as a function of mass flow and tool velocity (Orlowski et al. 2013, Pantea 1999, Atkins 2009).

\section{MATERIALS AND METHODS}

\section{Materials}

Scots pine (Pinus sylvestris L.) samples (15 items) originating from the Forest Inspectorate Lipusz in the Baltic Natural Forest Region (PL) were used as experimental samples in the sawmill conditions. Samples were in the shape of rectangular blocks with dimensions of $100 \mathrm{~mm}(H)^{\prime} 50 \mathrm{~mm}(W)^{\prime} 2200$ $\mathrm{mm}(L)$ with moisture content MC $35 \%$, density $\rho=509,2 \mathrm{kgm}^{-3}$. The value of friction coefficient $m$ $=0,6$ for pine wood was taken according to Glass and Zelinka (2010). The shear yield stresses $\tau$, for perpendicular cutting and for longitudinal cutting, were as follows: $\tau_{\nu \perp}=24,82 \mathrm{MPa}$ and $\tau_{v \|}=18,40 \mathrm{MPa}$, and fracture toughness for the same directions were $R_{\perp}=1212,69 \mathrm{Jm}^{-2}$ and $R_{\|}=34,99^{\gamma / 1} \mathrm{Jm}^{-2}$. It should be emphasized that values of shear yield stresses and fracture toughness were obtained empirically in the cutting tests in the industrial conditions according to the methodology presented in the paper by Orlowski et al. (2015). Furthermore, cutting tests have been recommended for determination of the cut material properties as an alternative and effective way (Atkins 2005, Wang et al. 2013). 


\section{Machine and tool data}

The cutting experiment was carried out on the single shaft multi rip sawing machine PWR301 (TOS Svitavy, CZ) at the Complex sawmill in Dziemiany (the Baltic Natural Forest Region, PL). In this type of the circular sawing machine, circular saw blades are clamped on the shaft with collars, on the contrary to the machines with guided spline circular saws which are often used in the North America (Mohammadpanah and Hutton 2016b). The machine settings were as follows: number of saw blades $n_{b}=1$, spindle rotational speed $3800 \mathrm{rpm}$, cutting speed $v_{c}=69,64 \mathrm{~ms}^{-1}$, feed speed $v_{f}=40 \mathrm{~m} \times \mathrm{min}^{-1}$, (feed per tooth $0,58 \mathrm{~mm}$, average of uncut chip thickness $h=0,373 \mathrm{~mm}$ ), clearance of a circular saw blade over the workpiece $5 \mathrm{~mm}$, electric engine power $P_{E M}=45 \mathrm{~kW}$, cutting kinematics - up-sawing (conventional sawing). In those cutting conditions the uncut chip thickness starts at minimum and increases toward the end of the cut (Figure 1), it means that the feed direction of the workpiece is opposite to the rotation of circular saw blade (Figure 2).

Changes in current as a function of time during cutting and idling operations were measured with sampling frequency equal to $1 \mathrm{kHz}$. The details of the measurement system can be found in Appendix B. The cutting power was calculated as a difference of a total electric power $P_{\mathrm{ET}}$ and an electric idling power $P_{\text {Eid }}$. Since the measurements were carried out in one phase it was assumed that in other phases values of current have been the same. The real electric power can be calculated as (Engineering Tool Box 2014):

$$
P_{E}=\sqrt{3} \cdot U \cdot I \cdot P F
$$

where: $U$ is voltage $(\mathrm{V}, U=400 \mathrm{~V}), I$ is measured current $(\mathrm{A}), P F$ is power factor $(P F=\cos F)$. It was assumed that for the cutting process the value of $P F=0,8$ and for idling $P F$ was equal 0,3 .

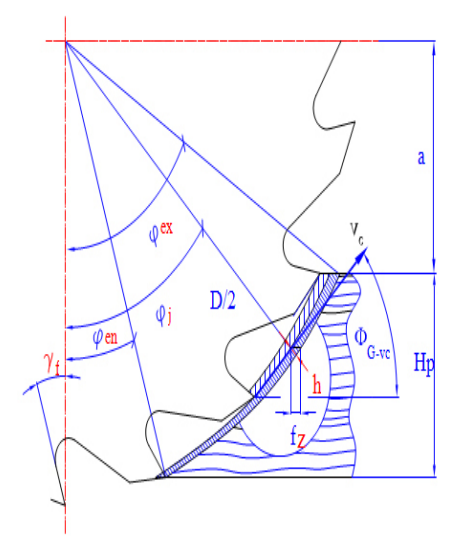

Figure 1. Sawing kinematics on circular sawing machine: $H_{p}$ workpiece height (depth of cut), a position of the workpiece, $\varphi_{j}$ angular tooth position, $\Phi_{\mathrm{G}-\mathrm{vc}}$ an angle between grains and the cutting speed direction, $\varphi_{e n}$ an angle of teeth entrance, $\varphi_{e x}$ an exit angle. 


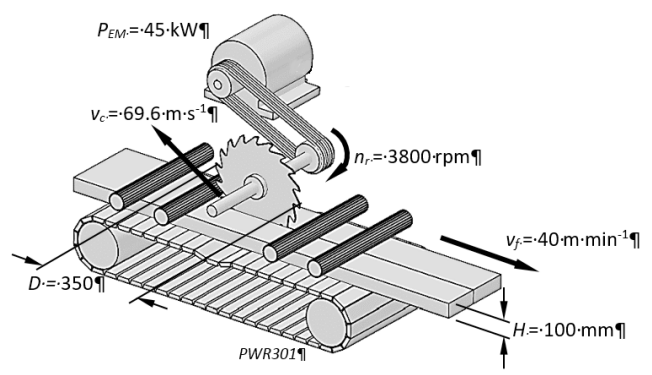

Figure 2. Scheme of the kinematic system of the single shaft multi rip sawing machine PWR301.

One circular saw blade was applied with data as follows: $350 \mathrm{~mm}(D) \times 80 \mathrm{~mm}(d) \times 2,5 \mathrm{~mm}(s)$, overall set $S_{t}=3,9 \mathrm{~mm}$ number of carbide tipped teeth $z=18$. The tooth geometry in the tool-in-hand system (Astakhov 2010) is shown in Figure 3, and the values of angles applied in the circular saw blade were as follows: the tool side flank $\alpha_{\mathrm{f}}=12^{\circ}$, the tool side rake $\gamma_{\mathrm{f}}=25^{\circ}$, the tool back flank $\alpha_{\mathrm{p} 1}^{\prime}=\alpha_{\mathrm{p} 2}$ $=2^{\circ}$, tool cutting edge angle $\kappa_{\mathrm{r}}=90^{\circ}$, minor tool cutting edge angle $\kappa_{\mathrm{r} 1}^{\prime}=\kappa_{\mathrm{r} 2}^{\prime}=2^{\circ}$, the cutting edge inclination angle $\lambda_{\mathrm{s}}=0^{\circ}$.

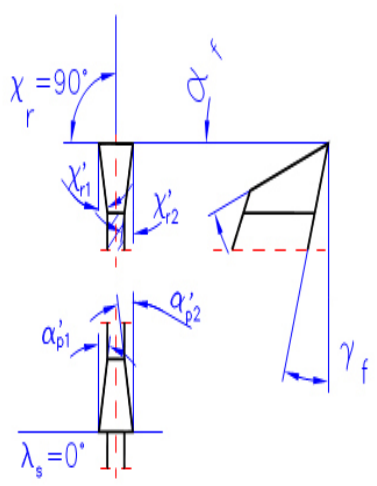

Figure 3. The circular saw blade tooth geometry in the tool-in-hand system: $\alpha_{\mathrm{f}}$ the tool side flank, $\alpha_{\mathrm{p}}$ the tool back flank, $\kappa_{\mathrm{r}}$ tool cutting edge angle, $\kappa_{\mathrm{r}}^{\prime}$ minor tool cutting edge angle, $\gamma_{\mathrm{f}}$ the tool side rake, $\lambda_{\mathrm{s}}$ the cutting edge inclination angle.

\section{Analysis of cutting power consumption}

Predictions of cutting model that includes work of separation in addition to plasticity and friction in the case of sawing pine wood on examined circular sawing machine have been carried out with the model presented in this paper. Besides uncut chip thicknesses changes, appropriate changes in shear yield stress and toughness with tooth/grain orientation had been taken into account. 
Moreover, additional computations have been done for the model proposed in the work by Orlowski et al. (2013), in which the sum of all uncut chip thicknesses of the all the teeth simultaneously engaged represented the mean uncut chip thickness. In predictions the raw material data, computed with Equations (7), was as follows: shear yield stresses $\tau_{\nu \Perp \perp}\left(\bar{\phi}=40,07^{\circ}\right)=23064099 \mathrm{~Pa}$ (for the tooth position at the average an angle of tooth contact with a workpiece $\bar{\varphi}$, which was calculated from $\left.\bar{\phi}=\frac{\phi_{e n}+\phi_{e x}}{2}\right)$, and fracture toughness $R_{\| \perp}\left(\bar{\varphi}=40,07^{\circ}\right)=523 \mathrm{Jm}^{-2}$. In this model the shear strain along the shear plane $\gamma$, the shear angle $\Phi_{c}$, and the friction correction $Q_{\text {shear }}$ were also calculated for the average angle of tooth contact with a workpiece $\bar{\varphi}$.

The both ploughing effect (Blackmann et al. 2013, Wang et al. 2013), and chip momentum were disregarded (Orlowski et al. 2013).

\section{RESULTS AND DISCUSSION}

Results of predictions of cutting power obtained with the use of a new developed cutting model that include work of separation in addition to plasticity and friction in the case of sawing of pine from the Forest Inspectorate Lipusz in the Baltic Natural Forest Region (PL) provenance with one circular saw blade, at the feed speed $v_{f}=40 \mathrm{~m} \cdot \mathrm{min}^{-1}$, for one full revolution of the tool (the first one), are shown in Figure 4. In this computation beside uncut chip thicknesses changes, appropriate changes in shear yield stress and toughness with tooth/grain orientation had been taken into account. For a stable condition of cutting power changes in the new developed model (N_M) the RMS value was computed, which was equal to $P_{c}$ (RMS_N_M) $=13774 \pm 147$ W. Cutting power estimation can be found in Appendix C.

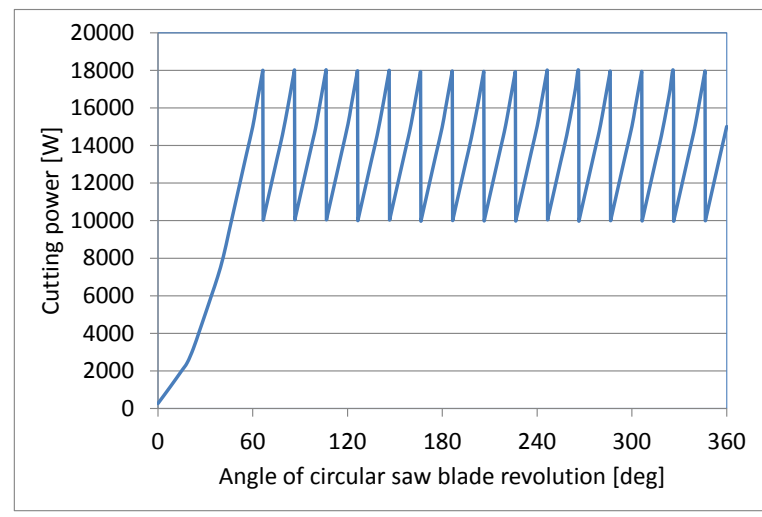

Figure 4. Predictions of cutting power obtained with the use of a new developed cutting model that include work of separation in addition to plasticity and friction for the circular sawing machine in the case of dry pine sawing with one circular saw blade.

In the model for circular sawing machine kinematics, presented in the paper by Orlowski et al. (2013), in which the sum of all uncut chip thicknesses of the all the teeth simultaneously engaged represented the mean uncut chip thickness, the predicted cutting power was equal to $P_{c}(\mathrm{Av}$ Thick $)=$ $13100 \pm 147 \mathrm{~W}$.

The cutting power measured in sawmill conditions was equal to $P_{c}$ (Exper) $=13563 \pm 45 \mathrm{~W}$. Figure 5 shows the comparison of cutting powers obtained: with the use of a new developed cutting model (N_M), in the experiment in sawmill conditions (Exper, an average value), and with a cutting model in which a mean value of uncut chip thicknesses is applied (AV Thick). 


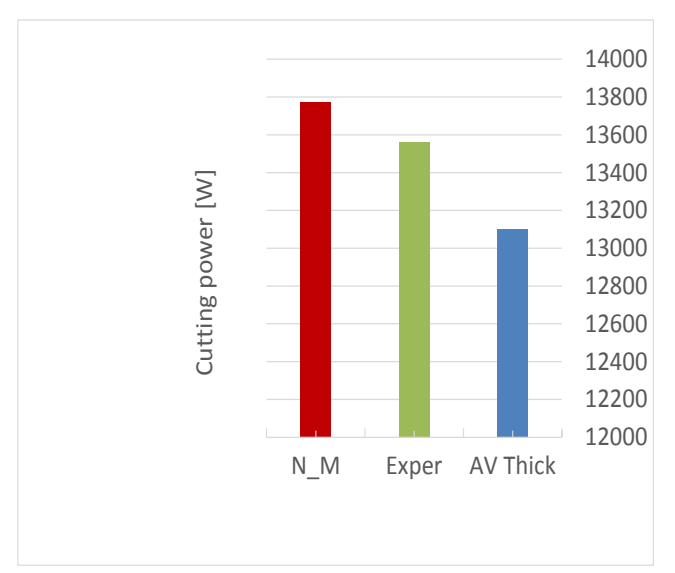

Figure 5. Comparison of cutting power obtained: with the use of a new developed cutting model (N_M), in the experiment in sawmill conditions (Exper), and with a cutting model in which a mean value of uncut chip thicknesses is applied (AV Thick).

This comparison revealed that the value of cutting power for a new model (N_M) is larger than the experimental one about $1,56 \%$ and the cutting power for the model (AV Thick) is lower about 3,41\%. For the both models, differences in relation to the experimental values are rather small. Nevertheless, the presented model is time consuming: the computation time for one revolution of the circular saw blade takes about $1800 \mathrm{~s}$, on the contrary for the cutting power model (AV Thick), which gives an insignificantly larger error of predictions, takes only $10 \mathrm{~s}$. Hence, this new-developed cutting model could be recommended for forecasting changes of cutting forces in case of dynamical analyses and unsteady cases. Moreover, for predictions of cutting power for circular sawing process, the model that applied in a sum of mean value of uncut chip thicknesses is highly recommended.

\section{CONCLUSIONS}

This paper shows that estimation of energetic effects using the newly-developed cutting model that include work of separation in addition to plasticity and friction is capable of predictions not only average values of cutting power but also its dynamical changes. Furthermore, this approach extends opportunities to modeling of the cutting process of with circular saw blades. The conducted analyses have demonstrated that values of RMS of cutting power obtained with the new developed model are slightly larger than experimental values. On the other hand computed values of cutting power with the use of the mean uncut chip thicknesses in the model are a bit lower from the empirical one. Nevertheless, since the time consuming process of computation for industrial application this model should not be recommended. Moreover, it could be changed by application of the more power computer, or the use of highly optimized simulation code dedicated to the process control units.

\section{ACKNOWLEDGEMENTS}

The authors wish to thank Professor Atkins of Reading University (UK) for helpful discussions. The theoretical part of this paper was presented at the $21^{\text {st }}$ International Wood Machining Seminar in Tsukuba, Japan, August 3-4, 2013. A comparison between the computed and empirical results has been presented as a poster at the Theo Murphy international scientific meeting "Cutting science in biology and engineering" organized by the Royal Society, Kavli Royal Society Centre, Chicheley, UK, October 26-27, 2015. The authors would like to acknowledge firms: the Complex Sawmill in 
Dziemiany (Poland) for Scot pine wood samples used in the experiments and other data on the sawing process, and the firm Aspi Tech Sp. z o.o., Sp. k. Suwalki (Poland) for circular saw blades data.

\section{REFERENCES}

Altintas, Y. 2000. Modeling approaches and software for predicting the performance of milling operations at MAL- UBC. Machining Science and Technology 4(3):445-478.

Ammar, A.A.; Bouaziz, Z.: Aghal, A. 2009. Modelling and simulation of the cutting forces for 2.5D pockets machining. Advances in Production Engineering \& Management 4(4):163-176.

Atkins, A.G. 2003. Modelling metal cutting using modern ductile fracture mechanics: quantitative explanations for some longstanding problems. Int J Mech Sci 45:373-396.

Atkins, A.G. 2005. Toughness and cutting: A new way of simultaneously determining ductile fracture toughness and strength. Eng Fracture Mech 72:849-860.

Atkins, A.G. 2009. The science and engineering of cutting. The mechanics and process of separating, scratching and puncturing biomaterials, metals and non-metals. Butterworth-Heinemann is an imprint of Elsevier, Oxford.

Atkins, A.G. 2016. Slice-push, formation of grooves and the scale effect in cutting. Interface Focus 6(3): DOI: 10.1098/rsfs.2016.0019

Astakhov, V.P. 2010. Chapter 2: Basic Definitions and Cutting Tool Geometry, Single Point Cutting Tools. In: Geometry of Single-point Turning Tools and Drills. Fundamentals and Practical Applications. [on line] Springer Series in Advanced Manufacturing. Springer London. pp. 54-101. <http://link.springer.com/chapter/10.1007\%2F978-1-84996-053-3_2> [accessed December 9, 2016]

Beljo-Lučić, R.; Goglia, V.; Pervan, S.; Dukić, I.; Risović, S. 2004. The influence of wood moisture content on the process of circular rip sawing. Part I: Power requirements and specific cutting forces. Wood Res 49(1):41-49.

Blackman, B.R.K.; Hoult, T.R.; Patel, Y.; Williams, J.G. 2013. Tool sharpness as a factor in machining tests to determine toughness. Eng Fracture Mech 101(2013):47-58.

Böllinghaus, T.; Byrne, G.; Cherpakov, B.I.; Chlebus, E.; Cross, C.E.; Denkena, B.; Dilthey, U.; Hatsuzawa, T.; Herfurth, K.; Herold, H. 2009. Manufacturing engineering. In: Springer Handbook of Mechanical Engineering, K.-H. Grote and E. K. Antonsson (eds.), Springer, Würzburg, pp. 609-656. DOI: 10.1007/978-3-540-30738-9_7

Budak, E. 2006. Analytical models for high performance milling. Part I: Cutting forces, structural deformations and tolerance integrity. Int J Mach Tools \& Manuf 46(12-13):1478-1488.

Chuchała, D.; Orlowski, K.A. 2016. Shear yield stresses and fracture toughness of Scots pine (Pinus sylvestris L.) according to the raw material provenance. Chip and Chipless Woodworking processes 10(1): 49-55 <http://www.tuzvo.sk/files/DF/katedry_df/kod/konferencia/2016/chuchala orlowski.pdf> [accessed December 13, 2016]

Cristóvão, L.; Ekevad, M.; Grönlund, A. 2013. Industrial sawing of Pinus sylvestris L.: Power consumption. BioRes. 8(4):6044-6053.

Engineering Tool Box. 2014. Three-Phase power equations. [on line] <http://www. engineeringtoolbox.com/three-phase-electrical-d_888.html> [accessed March 23, 2016] 
Gere, J.M. 2004. Mechanics of Materials. Thomson Learning Inc. <http://www.hljp.edu.cn/ attachment/20120820084627006.pdf> [accessed December 9, 2016]

Glass, S.V.; Zelinka, S.L. 2010. Moisture Relations and Physical Properties of Wood (Chapter 4). In: Wood Handbook - Wood as an Engineering Material. [on line] (Centennial Edition). General Technical Report FPL-GTR-190. Madison, WI: U.S. Department of Agriculture, Forest Service, Forest Products Laboratory. 508 p. <http://www.fpl.fs.fed.us/documnts/fplgtr/fpl_gtr190.pdf>

Hellström, L.M.; Biller, S.O.; Edvardsson, S.; Gradin, P. 2013. A theoretical and experimental study of the circular sawing process. Holzforschung 68(3):307-312.

Hlásková, L.; Orlowski, K.A.; Kopecký, Z.; Jedinák, M. 2015. Sawing processes as a way of determining fracture toughness and shear yield stresses of wood. BioRes 10(3):5381-5394.

Kopecký, L.; Hlásková, L.; Orlowski, K. 2014. An innovative approach to prediction energetic effects of wood cutting process with circular-saw blades. Wood Research 59(5):827-834.

Krilek, J.; Kováč, J.; Kučera, M. 2014. Wood crosscutting process analysis for circular saws. BioRes 9(1):1417-1429.

Kretschmann, D.E. 2010. Chapter 5, Mechanical Properties of Wood. In: Wood Handbook, Wood as an Engineering Material. General Technical Report FPL-GTR-190. Madison, WI: U.S. Department of Agriculture, Forest Service, Forest Products Laboratory. Centennial Edition. April 2010, 508 p.

Laternser, R.; Gänser, H.P.; Taenzer, L.; Hartmaier, A. 2003. Chip formation in cellular materials. Transactions of the ASME 125:44-49.

Marchal, R.; Mothe, F.; Denaud, L.E.; Thibaut, B.; Bleron, L. 2009. Cutting forces in wood machining - Basics and applications in industrial processes. A review COST Action E35 2004-2008: Wood machining - Micromechanics and fracture. Holzforschung 63(2):157-167. DOI 10.1515/ HF.2009.014.

Merhar, M.; Bučar, B. 2012. Cutting force variability as a consequence of exchangeable cleavage fracture and compressive breakdown of wood tissue. Wood Sci Technol 46(5):965-977.

Nairn, J.A. 2015. Numerical simulation of orthogonal cutting using the material point method. Eng Fracture Mech 149:262-275.

Nairn, J.A. 2016. Numerical modeling of orthogonal cutting: application to woodworking with a bench plane. Interface Focus 6(3): DOI: 10.1098/rsfs.2015.0110<http://www.cof.orst.edu/cof/wse/ faculty/Nairn/papers/WoodCutting.pdf $\geq$ [accessed March 29, 2016]

Markopoulos, A.P. 2013. Cutting mechanics and analytical modelling. In: Finite Element Method in Machining Processes. Springer, London, UK, pp. 11-27. DOI: 10.1007/978-1-4471-4330-7_2

Mohammadpanah, A.; Hutton, S.G. 2016a. Dynamics behavior of a guided spline spinning disk, subjected to conservative in-plane edge loads, analytical and experimental investigation. $J$ Vib Acoust 138(4):041005-041005-11. DOI: 10.1115/1.4033456.

Mohammadpanah, A.; Hutton, S.G. 2016b. Modeling and experimental verification of idling and cutting of guided spline circular saws. Global Journal of Researches in Engineering: A Mechanical and Mechanics Engineering 16(2):16p.

Orlicz, T. 1988. Obróbka drewna narzędziami tnącymi. (In Polish: Wood machining with cutting tools) Skrypty SGGW-AR w Warszawie, Wydawnictwo SGGW-AR, Warszawa. 
Orlowski, K.A.; Ochrymiuk, T. 2013. Revisiting the determination of cutting power while sawing of wood with circular saw blades by means of fracture mechanics. In: Proceedings of the $21^{\text {st }}$ International Wood Machining Seminar, August 4-7, 2011, Tsukuba, Japan. Eds. IWMS-21 Organizing Committee, The Japan Wood Research Society, pp. 46-55.

Orlowski, K.A.; Ochrymiuk, T.; Atkins, A.; Chuchala, D. 2013. Application of fracture mechanics for energetic effects predictions while wood sawing. Wood Sci Technol 47(5):949-963.

Orlowski, K.A.; Ochrymiuk, T.; Atkins, A. 2014. An innovative approach to the forecasting of energetic effects while wood sawing. Drvna Industrija 65(4):273-281.

Orlowski, K.; Ochrymiuk, T.; Sandak, J.; Sandak, A.; Riggio, M. 2015. Sawing process as a new alternative way of determining some wood properties. In: Proceedings of the $22^{\text {nd }}$ International Wood Machining Seminar/Volume 1/ ed. Hernandez R., Caceres C.B. Quebec City: Centre de Recherche sur les Materiaux Renouvelables Universite Laval, pp. 46-56.

Orlowski, K.A.; Palubicki, B. 2009. Recent progress in research on the cutting processes of wood. A review. COST Action E35 2004-2008: Wood machining - Micromechanics and fracture. Holzforschung 63(2):181-185. DOI 10.1515/HF.2009.015.

Otto, A.; Parmigiani, J. 2015. Velocity, depth-of-cut, and physical property effects on saw chain cutting. BioRes 10(4):7273-7291.

Pantea, R.C. 1999. Wood cutting system: modelling and process simulation. Mémoire présen té à la Faculté des études supérieures de l'université Laval pour l'obtention du grade de maître ès science (M.Sc.). Département de génie mécanique Faculté Des Sciences Et De Genie, Université Laval, (National Library of Canada).

Porankiewicz, B.; Goli, G. 2014. Cutting forces by Oak and Douglas fir machining. MaderasCienc Tecnol 16(2):199-216.

Wang, H.; Chang, L.; Ye, L.; Williams, J.G. 2013. Micro-cutting tests: a new way to measure the fracture toughness and yield stress of polymeric nanocomposites. In: Proceedings of the 13th International Conference on Fracture, June 16-21, 2013, Beijing, China <http://www.gruppofrattura.it/ ocs/index.php/ICF/icf13/paper/viewFile/11399/10778 $\geq$ [accessed 20 March 2016]

Williams, J.G.; Patel, Y.; Blackman, B.R.K. 2010. A fracture mechanics analysis of cutting and machining. Eng Fracture Mech 77:293-308.

Williams, J.G.; Patel, Y. 2016. Fundamentals of cutting. Interface Focus 6(3): June 2016. DOI: $10.1098 /$ rsfs. 2015.0108

Wyeth, D.J.; Atkins, A.G. 2009. Mixed mode fracture toughness as a separation parameter when cutting polymers. Eng Fracture Mech 76:2690-2697.

Wyeth, D.J.; Goli, G.; Atkins, A.G. 2009. Fracture toughness, chip types and the mechanics of cutting wood. A review: COST Action E35 2004-2008: Wood machining - Micromechanics and fracture. Holzforschung 63. DOI 10.1515/HF.2009.017 


\section{Appendix A}

According to (Atkins 2003) internal work is described by three parts: plasticity along shear plane (a), friction along the underside of the chip (b) and formation of new cut surface (c)

$$
F_{c} \cdot v_{c}=S_{t} \cdot \tau_{y} \cdot h \cdot v_{c} \cdot\left(\cot \left(\phi_{c}\right)-\tan \left(-\phi_{c}+y_{f}\right)\right)+\frac{F_{c} \cdot v_{c} \cdot \sin \left(\beta_{\mu}\right) \sin \left(\phi_{c}\right)}{\cos \left(\beta_{\mu}-y_{f}\right) \cos \left(-\phi_{c}+y_{f}\right)}+R_{c} \cdot S_{t} \cdot v_{c}
$$

a)

b)

From (A1) it can be obtained

$$
\frac{F_{c}}{S_{t} \cdot \tau_{y} \cdot h}=\frac{-\cos \left(\beta_{\mu}-y_{f}\right) \cos \left(-\phi_{c}+y_{f}\right)\left(\cot \left(\phi_{\mathrm{c}}\right)-\tan \left(-\phi_{\mathrm{c}}+y_{f}\right)+z\right)}{\sin \left(\beta_{\mu}\right) \sin \left(\phi_{c}\right)-\cos \left(\beta_{\mu}-y_{f}\right) \cos \left(-\phi_{\mathrm{c}}+y_{f}\right)}
$$

where

$$
Z=\frac{R}{\tau_{y} \cdot h}
$$

Hence, the parameter $Z$ makes $\Phi_{c}$ material dependent. According to the principle of minimum work, the work done in cutting should be at minimum, and thus its derivative should be zero, i.e.

$$
\frac{\partial F_{c} \cdot v_{c}}{\partial \phi_{c}}=v_{c} \frac{\partial F_{c}}{\partial \phi_{c}}=0
$$

and the cutting velocity $v_{c}$ is not equal to zero, it follows from Eq. (A4) that

$$
\frac{\partial F_{c}}{\partial \phi_{c}}=0
$$

Substituting Eq. (A2) to Eq. (A5) we can obtain

$$
\begin{aligned}
& \frac{\partial F_{c}}{\partial \phi_{c}}=\frac{\cos \left(\beta_{\mu}-y_{f}\right) \sin \left(-\phi_{c}+y_{f}\right)\left(\cot \left(\phi_{\mathrm{c}}\right)-\tan \left(-\phi_{\mathrm{c}}+y_{f}\right)+z\right)}{\cos \left(\beta_{\mu}-y_{f}\right) \cos \left(-\phi_{\mathrm{c}}+y_{f}\right)-\sin \left(\beta_{\mu}\right) \sin \left(\phi_{\mathrm{c}}\right)} \\
& +\frac{\cos \left(\beta_{\mu}-y_{f}\right) \cos \left(-\phi_{\mathrm{c}}+y_{f}\right)\left(-\left(\cot \left(\phi_{\mathrm{c}}\right)\right)^{2}+\left(\tan \left(-\phi_{\mathrm{c}}+y_{f}\right)\right)^{2}\right)}{\cos \left(\beta_{\mu}-y_{f}\right) \cos \left(-\phi_{\mathrm{c}}+y_{f}\right)-\sin \left(\beta_{\mu}\right) \sin \left(\phi_{\mathrm{c}}\right)} \\
& -\frac{\cos \left(\beta_{\mu}-y_{f}\right) \cos \left(-\phi_{\mathrm{c}}+y_{f}\right)\left(\cot \left(\phi_{\mathrm{c}}\right)-\tan \left(-\phi_{\mathrm{c}}+y_{f}\right)+z\right)\left(\cos \left(\beta_{\mu}-y_{f}\right) \sin \left(-\phi_{\mathrm{c}}+y_{f}\right)-\sin \left(\beta_{\mu}\right) \cos \left(\phi_{\mathrm{c}}\right)\right.}{\left(\cos \left(\beta_{\mu}-y_{f}\right) \cos \left(-\phi_{\mathrm{c}}+y_{f}\right)-\sin \left(\beta_{\mu}\right) \sin \left(\phi_{\mathrm{c}}\right)\right)^{2}}=0
\end{aligned}
$$

Or 


$$
\begin{gathered}
\left.\left(\begin{array}{l}
\left.\left.\sin \left(\phi_{\mathrm{c}}\right)\right)^{2}\left(\begin{array}{l}
\left.\left(\cos \left(\beta_{\mu}-y_{f}\right)\right)^{2}\left(\cos \left(-\phi_{\mathrm{c}}+y_{f}\right)\right)^{2}-2 \cos \left(\beta_{\mu}-y_{f}\right) \cos \left(-\phi_{\mathrm{c}}+y_{f}\right) \sin \left(\beta_{\mu}\right) \sin \left(\phi_{\mathrm{c}}\right)\right) \\
+1-\cos \left(\phi_{\mathrm{c}}\right)^{2}-\cos \left(\beta_{\mu}\right)^{2}+\cos \left(\beta_{\mu}\right)^{2} \cos \left(\phi_{\mathrm{c}}\right)^{2}
\end{array}\right)\right)^{-1} \\
\left(\begin{array}{l}
2 \sin \left(-\phi_{\mathrm{c}}+y_{f}\right) \sin \left(\beta_{\mu}\right) \cos \left(\phi_{\mathrm{c}}\right)-2 \sin \left(-\phi_{\mathrm{c}}+y_{f}\right) \sin \left(\beta_{\mu}\right)\left(\cos \left(\phi_{\mathrm{c}}\right)\right)^{2} \\
+\sin \left(-\phi_{\mathrm{c}}+y_{f}\right) Z \sin \left(\beta_{\mu}\right) \sin \left(\phi_{\mathrm{c}}\right)-\sin \left(-\phi_{\mathrm{c}}+y_{f}\right) Z \sin \left(\beta_{\mu}\right) \sin \left(\phi_{\mathrm{c}}\right)\left(\cos \left(\phi_{\mathrm{c}}\right)\right)^{2} \\
--2 \cos \left(-\phi_{\mathrm{c}}+y_{f}\right)\left(\cos \left(\phi_{\mathrm{c}}\right)\right)^{2} \sin \left(\beta_{\mu}\right) \sin \left(\phi_{\mathrm{c}}\right)-\cos \left(\beta_{\mu}-y_{f}\right)+\cos \left(\beta_{\mu}-y_{f}\right)\left(\cos \left(\phi_{\mathrm{c}}\right)\right)^{2} \\
+\cos \left(\beta_{\mu}-y_{f}\right)\left(\cos \left(-\phi_{\mathrm{c}}+y_{f}\right)\right)^{2}-\cos \left(-\phi_{\mathrm{c}}+y_{f}\right) Z \sin \left(\beta_{\mu}\right) \cos \left(\phi_{\mathrm{c}}\right) \\
+\cos \left(-\phi_{\mathrm{c}}+y_{f}\right) Z \sin \left(\beta_{\mu}\right)\left(\cos \left(\phi_{\mathrm{c}}\right)\right)^{2}
\end{array}\right)=0
\end{array}\right)\right)
\end{gathered}
$$

Manipulating the trig function we obtain equation proposed in (Atkins 2003)

$$
\begin{aligned}
& \left(1-\frac{\sin \left(\beta_{\mu}\right) \sin \left(\phi_{c}\right)}{\cos \left(-\beta_{\mu}+y_{f}\right) \cos \left(-\phi+y_{f}\right)}\right)\left(\frac{1}{\cos \left(-\phi_{c}+y_{f}\right)^{2}}-\frac{1}{\sin \left(\phi_{c}\right)^{2}}\right) \\
& +\frac{\left(\cot \left(\phi_{c}\right)-\tan \left(-\phi_{c}+y_{f}\right)+Z\right) \sin \left(\beta_{\mu}\right)\left(\frac{\cos \left(\phi_{c}\right)}{\cos \left(-\phi_{c}+y_{f}\right)}+\frac{\sin \left(\phi_{c}\right) \sin \left(-\phi+y_{f}\right)}{\cos \left(-\phi_{c}+y_{f}\right)^{2}}\right)}{\cos \left(-\beta_{\mu}+y_{f}\right)}=0
\end{aligned}
$$

\section{Appendix B}

Cutting power measurement system. The cutting power measurements were performed using a system consisting of a probe AC/DC current transducer DHR 100C10 (LEM USA Inc.), high-accuracy isothermal terminal block NI SCXI 1328 (National Instruments, USA), an 8-channel isolation amplifier NI SCXI 1125 (National Instruments, USA), 4-Slot Chassis NISCXI 1000DC (National Instruments, USA) and computer with the NI PCI 6281 card (National Instruments, USA).

\section{Appendix C}

Based on equation (3) the error of the cutting power could be expresses in the form

$$
\delta P_{c}=\frac{v_{c} S_{t}}{Q s h e a r}\left(y \cdot h \cdot \delta \tau_{y \| \perp}+\delta R_{\| \perp}\right)
$$

Where: $\delta \tau_{y \| \perp}$ and $\delta R_{\| \perp}$ are the shear yield stress and fracture toughness errors of the following values (Chuchala and Orlowski 2016): $\delta \tau_{y \| \perp}=0,27 \mathrm{MPa}$ and $\delta R_{\| \perp}=384 \mathrm{~J} / \mathrm{m}^{2}$. 
Assuming average values depending on angular position variables in Eq. (C1), it can be obtained a value of the estimated cutting power error $\delta P_{c}=147 \mathrm{~W}$. 